\title{
Noise risk assessment in a bottling line of a modern Sicilian winery
}

\author{
Mariangela Vallone, Felice Pipitone, Salvatore Amoroso, Pietro Catania \\ University of Palermo. Dipartimento di Scienze Agrarie e Forestali, Palermo, Italy
}

\begin{abstract}
In wine industry, bottling is a phase of the production cycle characterized by high levels of noise mostly due to repeated collisions between the bottles. In Italy the Law Decree 81/2008 defined the requirements for assessing and managing noise risk, identifying a number of procedures to be adopted at different noise levels to limit workers exposure. This study aims at evaluating the equivalent and peak noise level inside the bottling plant area of a modern Sicilian winery. In particular, the influence of the working capacity (number of bottles produced per hour) on noise levels was evaluated. We considered three test conditions: T1 with working capacity of 4,000 bottles per hour, T2 with working capacity of 5,000 bottles per hour and T3 with working capacity of 6,000 bottles per hour. Fifteen measurement points were identified inside the bottling area. The instrument used for the measurements is a precision integrating portable sound level meter, class 1, model HD2110L by Delta 0HM, Italy. The tests were performed in compliance with ISO 9612 and ISO 9432 regulations. The results show that as bottling plant working capacity increases, noise level increases. The measured sound levels exceed the limits allowed by the regulations in all the test conditions; values exceeding the threshold limit of $80 \mathrm{~dB}(\mathrm{~A})$ were recorded coming up to a maximum value of $95 \mathrm{~dB}(\mathrm{~A})$ in test $\mathrm{T} 3$. In this case, the operator working along the bottling line is obliged to wear the appropriate Personal Protective Equipment.
\end{abstract}

\footnotetext{
Correspondence: Mariangela Vallone, University of Palermo. Dipartimento di Scienze Agrarie e Forestali Viale Delle Scienze Edificio 4, 90128 Palermo, Italy.

Tel. +39.91.23865609.

E-mail: mariangela.vallone@unipa.it
}

Key words: bottling line, noise risk, winery

Contributions: the authors contributed equally.

Conflict of interests: the authors declare no potential conflict of interests.

Conference presentation: part of this paper was presented at the $10^{\text {th }}$ Italian Conference AIIA (Associazione Italiana di Ingegneria Agraria), 2013 September 8-12, Viterbo, Italy.

(C) Copyright M. Vallone et al., 2013

Licensee PAGEPress, Italy

Journal of Agricultural Engineering 2013; XLIV(s2):e140

doi:10.4081/jae.2013.s2.e140

This article is distributed under the terms of the Creative Commons Attribution Noncommercial License (by-nc 3.0) which permits any noncommercial use, distribution, and reproduction in any medium, provided the original author(s) and source are credited.

\section{Introduction}

In wine industry, bottling is a phase of the production cycle characterized by high levels of noise (Lowe and Elkin, 1986; Ologe et al., 2008; Oyedepo and Saadu A., 2010) mostly due to repeated collisions between the bottles. Bottle transport has been identified as one of the main noise-sources in bottling plants (Sivak, 1982); the noise is emitted from the clashing bottles.

Directive 2003/10/EC of the European Parliament was enacted on the minimum health and safety requirements regarding the exposure of workers to the risks arising from physical agents (noise).

It stipulates an upper average limit of noise exposure of a worker during an eight hours shift of work at $85 \mathrm{~dB}(\mathrm{~A})$. This level is supposed to inhibit hearing impairments of workers (Moselhi et al., 1979). Even the ILO (International Labour Organization) indication agree with this.

In Italy, Law Decree 81/2008 has defined the obligations of noise assessment and risk management, identifying a series of procedures to be adopted at the different noise levels in order to limit the exposure of workers. Excessive noise, in fact, is a global occupational health hazard with considerable social and physiological impacts, including noise-induced hearing loss (NIHL) (Deborah et al., 2005).

Some authors carried out researches aiming at evaluating innovative systems to implement the control of multi-lane conveyors in bottling plants for a noise level reduction. In particular, Sorgatz et al. (2012) developed a continuous control algorithm to further reduce the noise emission of multi-lane bottle conveyors. They obtained that the continuous control is less noisy compared with the jam switch control evaluating noise in five measuring points because with the innovative system the velocity of the belts decreased and the impact velocity of the bottles reduced.

In literature, there are few studies concerning the noise level assessment in a bottling plant of a winery. Therefore, this study aims at evaluating the equivalent and peak noise level inside the bottling plant area of a modern Sicilian winery. In particular, the influence of the working capacity (number of bottles produced per hour) on noise levels was evaluated.

\section{Materials and methods}

\section{Bottling plant}

The bottling plant examined in this study is automated, schematically consisting of the following machines:

- depalletizer (loading empty bottles);

- washing - filling - capping machine;

- washing and drying machine (cleaning the outside of the bottle);

- capper;

- labeling machine;

- vertical cartoner;

- forming machine;

- hive inserting machine;

- closing machine; 
- pallettizer;

- wrapping machine.

Five operators control the different phases of the process.

\section{Instruments used during the tests}

The instrument used in the tests is a precision integrating portable sound level meter by Delta OHM, Italy, model HD2110L (Figure 1).

\section{Experimental tests}

The winery bottling area has an almost rectangular plant with an area of approximately $800 \mathrm{~m}^{2}$. The 15 measurement points were located through a square mesh whose sides are orthogonal with respect to the sides of the room (Figure 2).

The sound level meter was positioned at a height of $1.50 \mathrm{~m}$ from the ground with the aid of a tripod; each measurement had a duration of 2 minutes (the case of stationary noise source) and the parameters were analyzed at intervals of 0.5 seconds.

We measured A-weighted time-averaged sound pressure level $\left(\mathrm{L}_{\text {Aeq }}\right)$ and $\mathrm{C}$-weighted peak sound pressure level $\left(\mathrm{L}_{\mathrm{cpk}}\right)$. In addition, a Cweighted ex post measurement in the point of greatest noise was realized.

As required by article 189 of Law Decree 81/2008, the worker does not have to be exposed to $\mathrm{L}_{\mathrm{Eex}, 8 \mathrm{~h}}$ values (occupational noise) reported to 8 working hours higher than $80 \mathrm{~dB}(\mathrm{~A})$ and to $\mathrm{L}_{\mathrm{Cpk}}$ exceeding $135 \mathrm{~dB}(\mathrm{C})$.

$\mathrm{L}_{\mathrm{Eex}, 8 \mathrm{~h}}$ values is given by the following equation:

$$
\mathrm{L}_{\mathrm{EX}, 8 \mathrm{~h}}=\mathrm{L}_{\mathrm{Aeq}, \mathrm{Te}}+10 \log \left(\mathrm{T}_{\mathrm{e}} / \mathrm{T}_{0}\right)
$$

where $\mathrm{Te}$ is the effective duration, in hours, of the working day and $\mathrm{T}_{0}$ is the reference duration equal to 8 hours. In this case Te was assumed to be 7.5 hours.

Before each series of measurements the instrument calibration was performed applying a sound calibrator. The collected data were downloaded to the PC for further processing.

Three test conditions, corresponding to different bottling plant working capacity (as number of bottles per hour) were realized, named T1, $\mathrm{T} 2$ and $\mathrm{T} 3$ :

- T1: working capacity 4,000 bottles per hour;

- T2: working capacity 5,000 bottles per hour;

- T3: working capacity 6,000 bottles per hour.

Tests were carried out in triplicates. Analysis of variance and Tukey's test were performed using Statgraphics Centurion by Statpoint inc., USA.

\section{Results and discussion}

A-weighted time-averaged sound pressure levels $\left(\mathrm{L}_{\text {Aeq }}\right)$ for test $\mathrm{T} 1$ are shown in Figure 3 for the 15 measuring points.

Noise pressure values obtained in T1 show a minimum of $82.4 \mathrm{~dB}(\mathrm{~A})$ in the measurement point number 7 , near to the palletizer, and a maximum of $89.6 \mathrm{~dB}(\mathrm{~A})$ in the measurement point number 13 , which is located immediately before the capping machine. Figure 3 shows that the exposure limit value established by the article 189 of Law Decree $81 / 2008$ (equal to $87 \mathrm{~dB}(\mathrm{~A})$ ) is reached only in measurement points number 4 and 13 which are located in the vicinity of the conveyor bends. The upper action value of $85 \mathrm{~dB}(\mathrm{~A})$ is instead achieved in all the measuring stations with the exception of $2,7,8,10$ and 14 while the lower action value (equal to $80 \mathrm{~dB}(\mathrm{~A})$ ) is exceeded in all the measuring points. Statistical analysis $(\mathrm{p}<0.05)$ shows significant differences between all the measuring points with the exception of 1-12, 1-3, 8-10, $3-12,6-12,5-15$.

Figure 4 shows the A-weighted time-averaged sound pressure levels ( $\mathrm{L}_{\mathrm{Aeq}}$ ) for test $\mathrm{T} 2$.

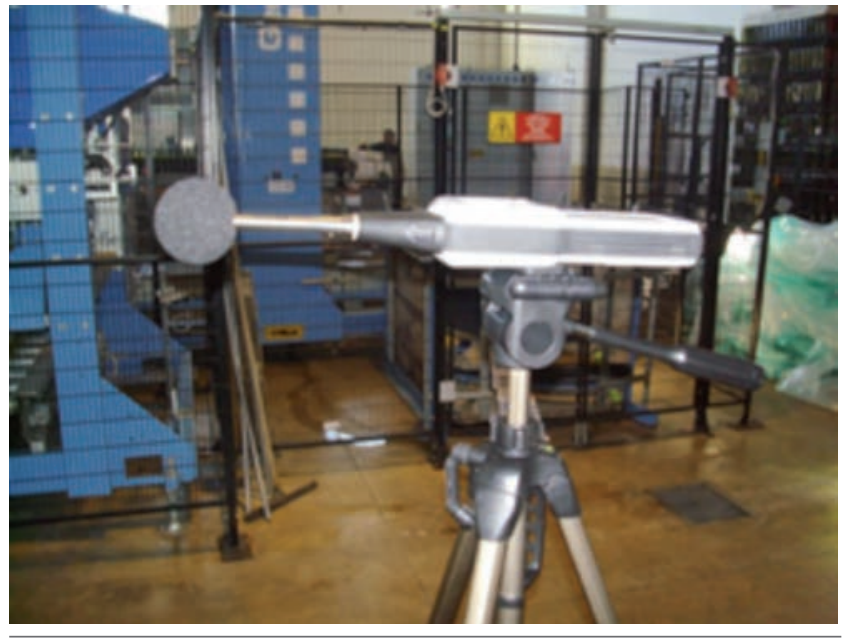

Figure 1. HD2110L integrating portable sound level meter by Delta OHM, Italy.

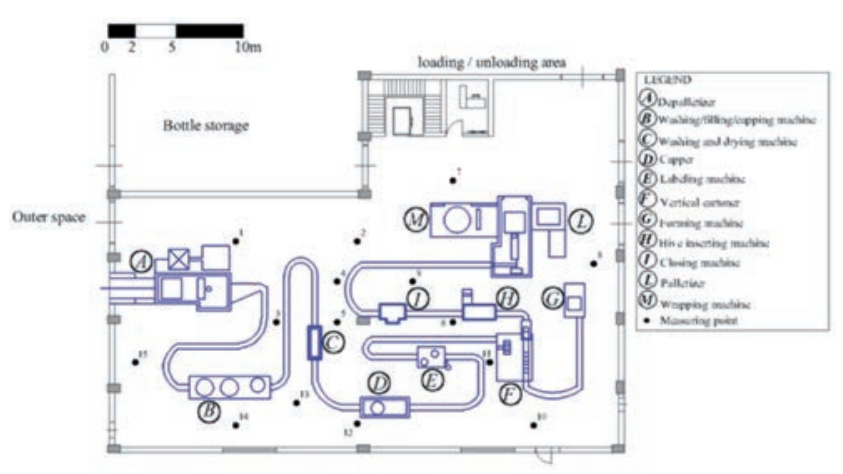

Figure 2. Plan lay out of the bottling area and measurements points.

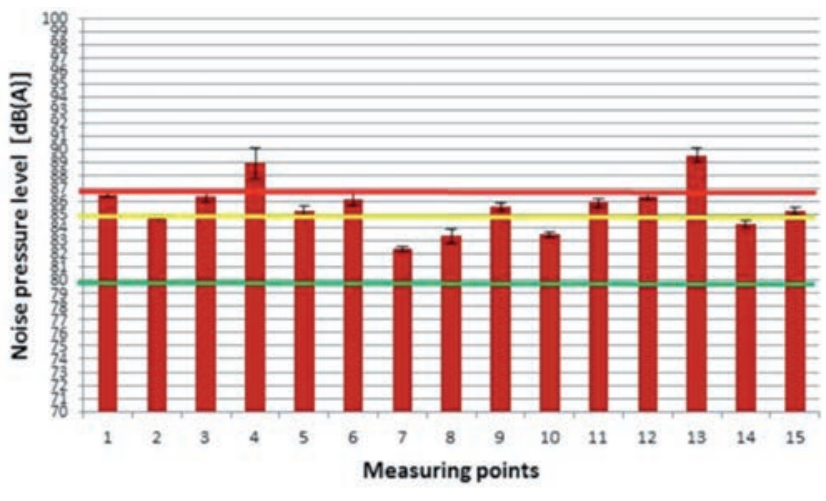

Figure 3. Noise pressure levels $\left(\mathrm{L}_{\text {Aeq }}\right)$ for test $\mathrm{T} 1$ in the 15 measuring points (data are reported as means \pm standard deviations of the three replicates). 
Noise pressure values obtained in $\mathrm{T} 2$ show a minimum of $83.8 \mathrm{~dB}(\mathrm{~A})$ in the measurement point number 7 , near to the palletizer, and a maximum of $93.4 \mathrm{~dB}(\mathrm{~A})$ in the measurement point number 4 , which is located immediately after the closing machine. The exposure limit value is reached in measurement points number $3,4,5,9,11,12,13$ and 15. The upper action value is achieved in all the measuring stations with the exception of number 7 while the lower action value is exceeded in all the measuring points. Statistical analysis $(p<0.05)$ shows significant differences between all the measuring points with the exception of 2-6, 2-14, 5-15.

Figure 5 shows the A-weighted time-averaged sound pressure levels ( $\mathrm{L}_{\text {Aeq }}$ ) for test T3.

Noise pressure values obtained in $\mathrm{T} 3$ show a minimum of $84.5 \mathrm{~dB}(\mathrm{~A})$ in the measurement point number 7 , near to the palletizer, and a maximum of $95.6 \mathrm{~dB}(\mathrm{~A})$ in the measurement point number 4 , which is located immediately after the closing machine. The exposure limit value is reached in all the measurement points with the exception of 7 , 8 and 10 . As obtained in T2, the upper action value is achieved in all the measuring stations with the exception of number 7 while the lower action value is exceeded in all the measuring points. Statistical analysis $(\mathrm{p}<0.05)$ shows significant differences between all the measuring points with the exception of 1-2, 1-9, 1-14, 2-9, 2-14, 9-14, 9-15, 14-15.

Data related to the three tests are reported together in Figure 6 in order to highlight the differences, if any, between the noise levels achieved in the various measurement points. Always note statistically significant differences for $\mathrm{p}=0.05$ between the tests T1-T2 (with the exception of the measuring point 6) and T1-T3. The comparison between T2 and T3, however, shows that not all the measurement stations are statistically significant different. Differences were found, for example, at station 4, but not in 13 .

The spectral analysis regarding the measurement stations 4 and 13 is reported in Figure 7 for the three test conditions.

C-weighted peak sound pressure levels $\left(\mathrm{L}_{\mathrm{Cpk}}\right)$.obtained in the different tests are shown in Figure 8.

Neither the exposure limit value equal to $140 \mathrm{~dB}(\mathrm{C})$ according to the cited art. 189 of Law Decree 81/2008, or the upper and lower action values (equal to $137 \mathrm{~dB}(\mathrm{C})$ and $135 \mathrm{~dB}(\mathrm{C})$ ) are reached or exceeded in any of the measurement points. No statistically significant differences were found between the three tests.

The data obtained by the measurements allowed us to have the equal loudness curves for the tests carried out, thereby evaluating the zones with equivalent average sound levels. Figure 9 shows the map related to T1.

With reference to T2 (Figure 10), you may notice an increase in the noise level compared to T1.

The results of T3 (Figure 11), show overall noise levels higher than the two test conditions discussed above.

\section{Conclusions}

The results of the experiments carried out allow us to affirm that increasing the bottling plant working capacity the noise level increases. The highest noise pressure values were obtained in the measurement point number 4 and 13, respectively located immediately after the closing machine and before the capping machine; this occurs in the three test conditions. The results also show that noise pressure values measured during the three tests are always higher than the lower action value identified by law, equal to $80 \mathrm{~dB}(\mathrm{~A})$ In particular, the upper action value equal to $85 \mathrm{~dB}(\mathrm{~A})$ is reached in all the measurement points except 2, 7, 8, 10 and 14 in T1. In T2 and T3 this value is reached in every station except number 7 . The exposure limit value of $87 \mathrm{~dB}(\mathrm{~A})$ is reached in T1 only in the stations 4 and 13 , in T2 in $3,4,5,9,11,12$,
13 measurement points and in T3 in all the stations except 7,8 and 10. As a consequence, the use of appropriate PPE is required when limits imposed by the regulations are exceeded.

With reference to the peak values, neither the exposure limit value equal to $140 \mathrm{~dB}(\mathrm{C})$, or the upper and lower action values (equal to 137 $\mathrm{dB}(\mathrm{C})$ and $135 \mathrm{~dB}(\mathrm{C}))$ are reached or exceeded in any of the measurement points.

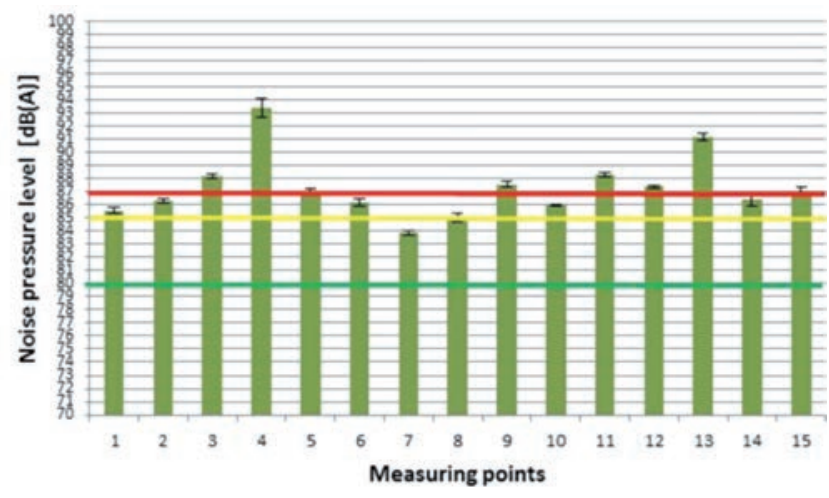

Figure 4. Noise pressure levels $\left(\mathrm{L}_{\text {Aeq }}\right)$ for test $T 2$ in the 15 measuring points (data are reported as means \pm standard deviations of the three repli-

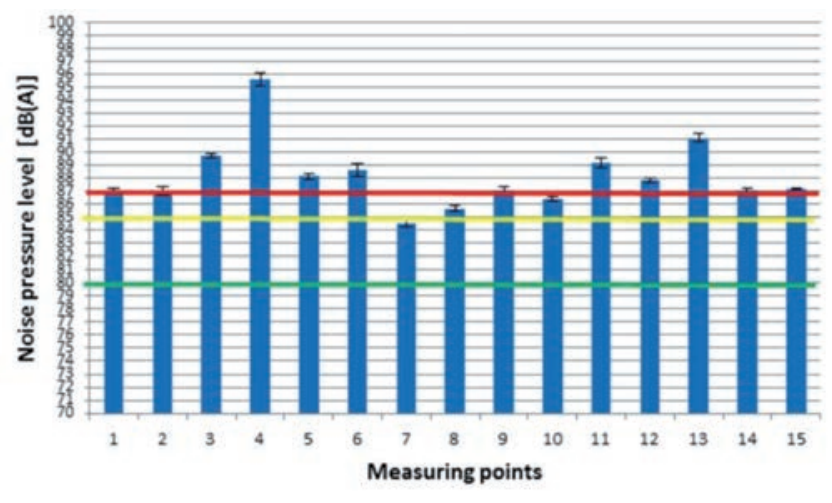

Figure 5. Noise pressure levels $\left(\mathrm{L}_{\mathrm{Aeq}}\right)$ for test $\mathrm{T} 3$ in the 15 measuring points (data are reported as means \pm standard deviations of the three replicates).

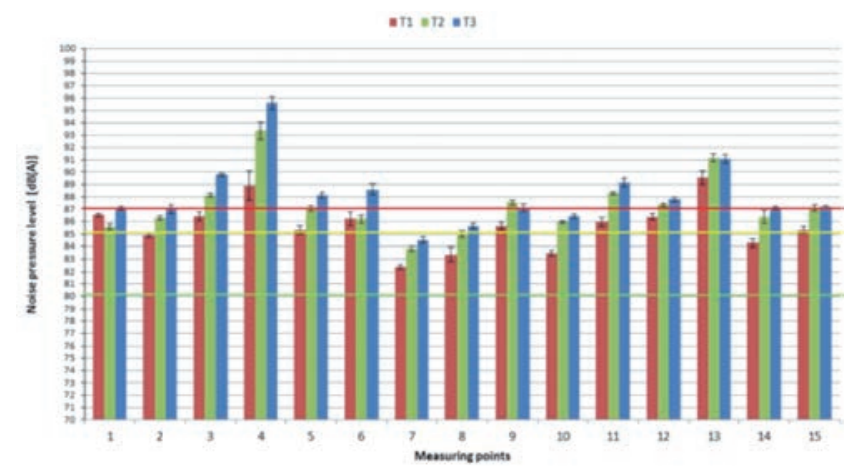

Figure 6. Noise pressure levels $\left(\mathrm{L}_{\text {Aeq }}\right)$ for tests $\mathrm{T} 1, \mathrm{~T} 2$ and $\mathrm{T} 3$ in the 15 measuring points (data are reported as means \pm standard deviations of the three replicates). 

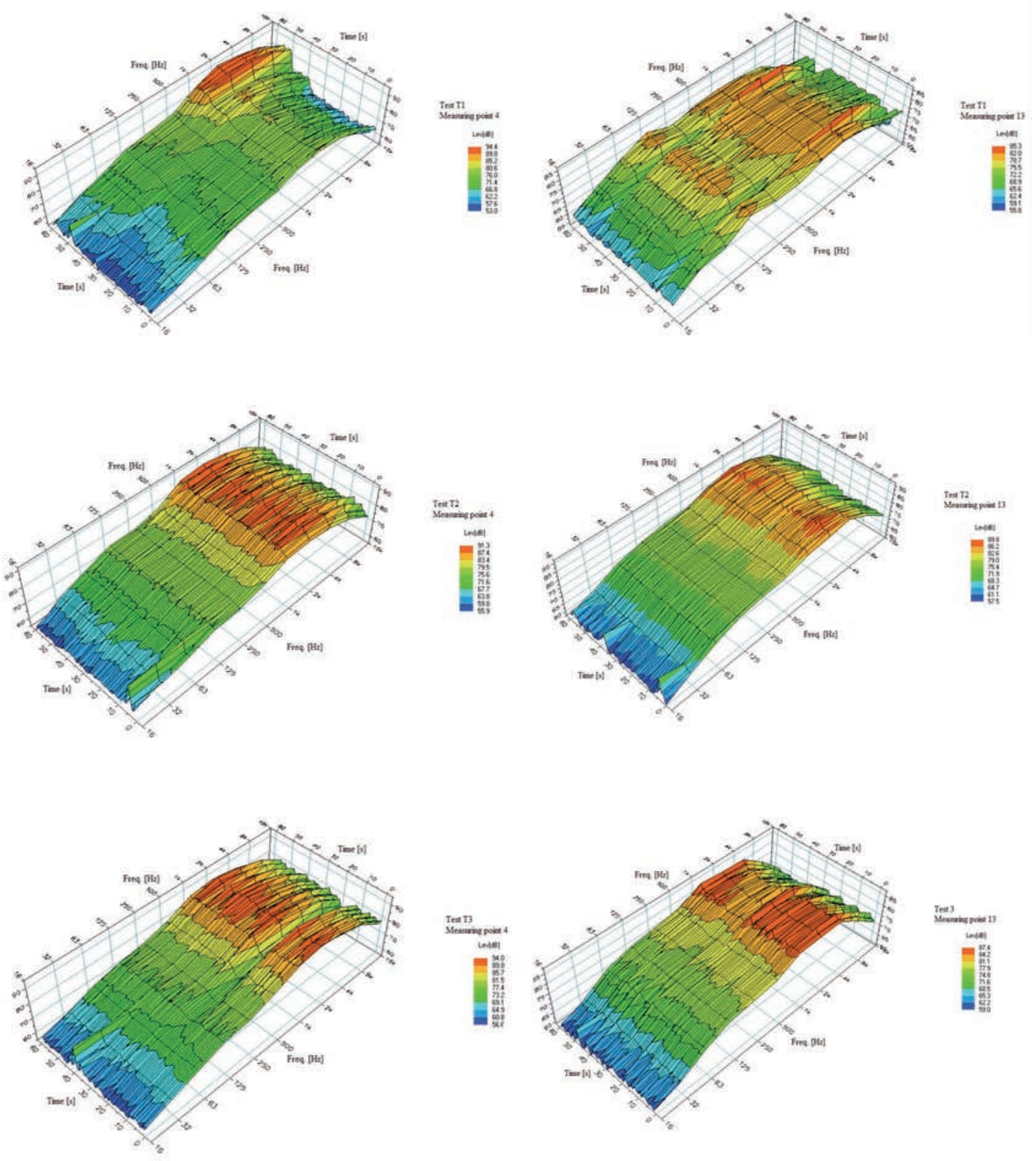

Figure 7. Spectral analysis regarding the measurement stations 4 and 13 for T1, T2 and T3.

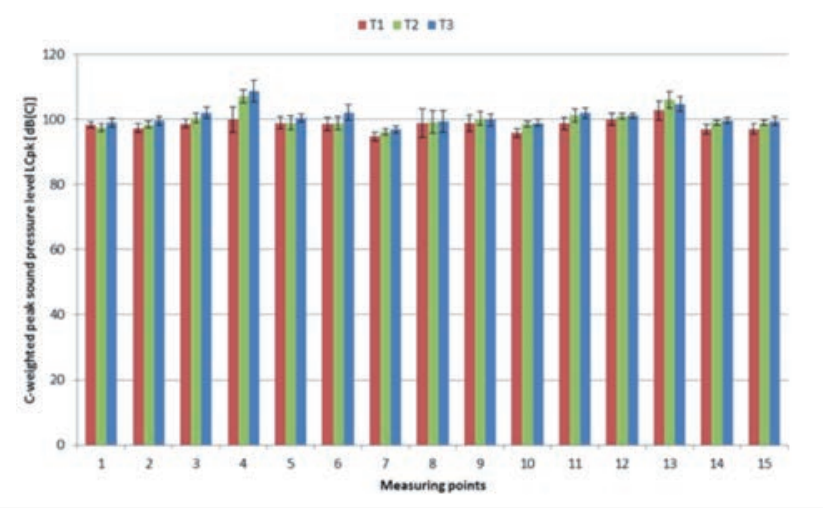

Figure 8. C-weighted peak sound pressure leves $\left(\mathrm{L}_{\mathrm{Cpk}}\right)$.obtained in the tests T1, T2 and T3.

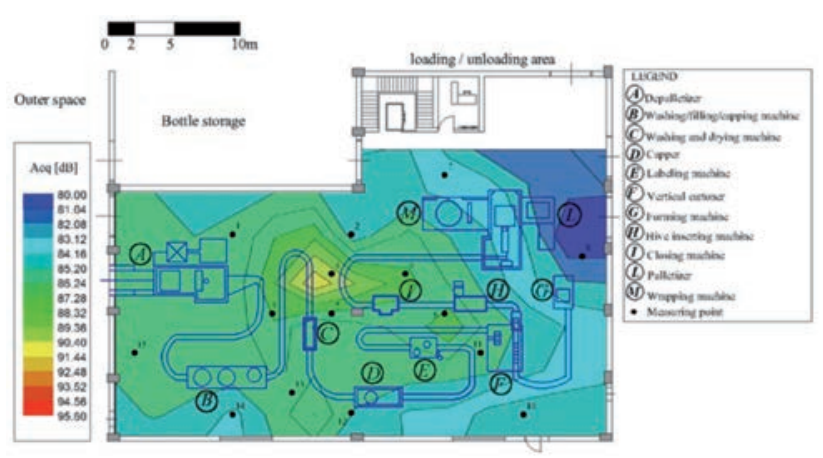

Figure 9. Map of equal loudness curves for test T1. 


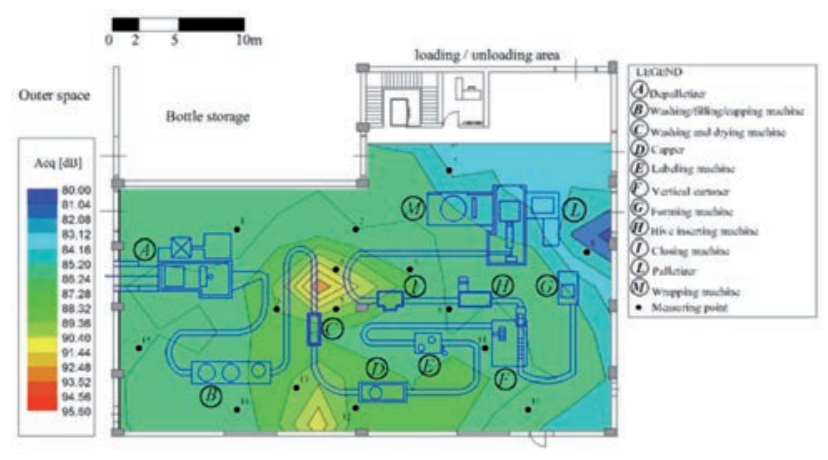

Figure 10. Map of equal loudness curves for test T2.

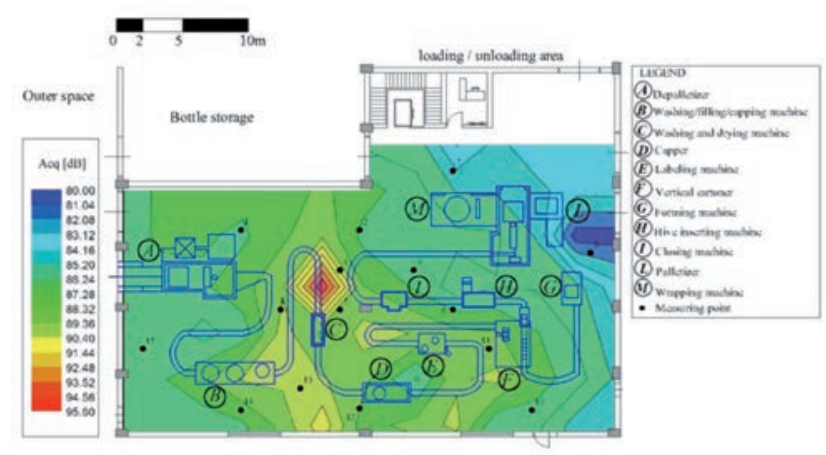

Figure 11. Map of equal loudness curves for test T3.

\section{References}

Deborah, I. N., Robert, Y. N., Marison, C. B., \& Marilyn, F. The global burden of occupational noise induced hearing loss. American Journal of Industrial Medicine, 2005, 48(6), 446-458.

European Parliament and Council, Directive 2003/10/EC of the European Parliament and of the Council of 6 February 2003 on the minimum health and safety requirements regarding the exposure of workers to the risks arising from physical agents (noise).

International Labour Organization (ILO). Health, Safety and Environment: A Series of Trade Union Education Manuals for Agricultural Workers, 2004, ISBN:92-2-115 192-1.

Law Decree 81, 9 April 2008 of the Italian Republic.

Lowe C.M., Elkin W.I. Centenary review beer packaging in glass and recent developments. J. Inst. Brew., November-December, 1986, Vol. 92, 517-528.

Moselhi M., El-Sadik, Y. M. and El-Dakhakhny, A., A six year follow up study for evaluation of the $85 \mathrm{dBA}$ safe criterion for noise exposure. Am. Ind. Hyg. Assoc. J., 1979, 40(5), 424-426.

Ologe F.E., Olajide T.G., Nwawolo C.C., Oyejola B.A. Deterioration of noise-induced hearing loss among bottling factory workers, Journal of Laryngology and Otology, 2008, 122(8), 786-794.

Oyedepo 0.S., Saadu A.A., Assessment of noise level in sundry processing and manufacturing industries in Ilorin metropolis, Nigeria. Environ Monit Assess, 2010, 162, 453-464.

Sivak, R. F., Noise control design for packaging. Tech. Q. Master Brew. Assoc. Am., 1982, 19(3), 115-121.

Sorgatz, A., Voigt, T., Continuous control for buffering conveyors in beverage bottling plants. Packaging Technology and Science, 2012, DOI: $10.1002 /$ pts.1997 